
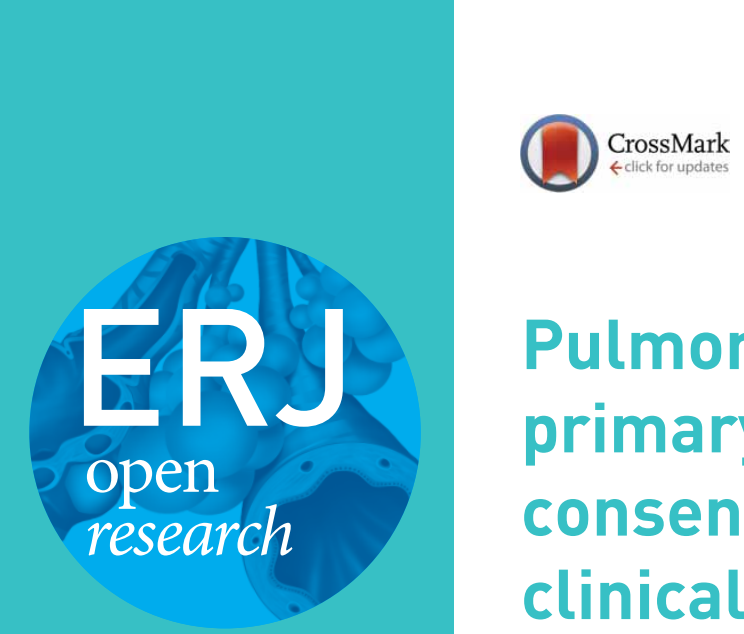

\title{
Pulmonary exacerbations in patients with primary ciliary dyskinesia: an expert consensus definition for use in clinical trials
}

\author{
Jane S. Lucas (10 ${ }^{1}$, Florian Gahleitner ${ }^{1}$, Adelina Amorim²,3 ${ }^{2}$, Mieke Boon ${ }^{4}$, \\ Philippa Brown ${ }^{5}$, Carolina Constant $\mathbb{1}^{6}$, Simon Cook ${ }^{5}$, Suzanne Crowley ${ }^{7}$, \\ Damien M.S. Destouches ${ }^{8}$, Ernst Eber ${ }^{9}$, Huda Mussaffi ${ }^{10}$, Eric Haarman ${ }^{11}$, \\ Amanda Harris ${ }^{1}$, Cordula Koerner-Rettberg ${ }^{12}$, Claudia E. Kuehni (1) ${ }^{13}$, \\ Philipp Latzin (1) ${ }^{14}$, Michael R. Loebinger ${ }^{15,16}$, Natalie Lorent ${ }^{17}$, \\ Bernard Maitre ${ }^{18}$, Antonio Moreno-Galdó ${ }^{19}$, Kim G. Nielsen ${ }^{20}$, Uğur Özçelik ${ }^{21}$, \\ Lue Katrine Drasbæk Philipsen ${ }^{20}$, Petr Pohunek ${ }^{22}$, Eva Polverino ${ }^{23}$, \\ Jessica Rademacher ${ }^{24}$, Phil Robinson ${ }^{25}$, Deborah Snijders ${ }^{26}$, \\ Panayiotis Yiallouros ${ }^{27}$ and Siobhán B. Carr $\mathbb{1}^{28}$ on behalf of the BEAT-PCD \\ network
}

ABSTRACT Pulmonary exacerbations are a cause of significant morbidity in patients with primary ciliary dyskinesia (PCD) and are frequently used as an outcome measure in clinical research into chronic lung diseases. So far, there has been no consensus on the definition of pulmonary exacerbations in PCD.

30 multidisciplinary experts and patients developed a consensus definition for children and adults with PCD. Following a systematic review, the panel used a modified Delphi process with a combination of faceto-face meetings and e-surveys to develop a definition that can be used in research settings for children and adults with PCD.

A pulmonary exacerbation was defined by the presence of three or more of the following seven items: 1) increased cough, 2) change in sputum volume and/or colour, 3) increased shortness of breath perceived by the patient or parent, 4) decision to start or change antibiotic treatment because of perceived pulmonary symptoms, 5) malaise, tiredness, fatigue or lethargy, 6) new or increased haemoptysis, and 7) temperature $>38^{\circ} \mathrm{C}$.

The consensus panel proposed that the definition should be used for future clinical trials. The definition should be validated and the usability assessed during these studies.

@ERSpublications

A consensus definition for pulmonary exacerbations in children and adults with PCD for use in clinical trials http://ow.ly/Rcfr30n4Gn4

Cite this article as: Lucas JS, Gahleitner F, Amorim A, et al. Pulmonary exacerbations in patients with primary ciliary dyskinesia: an expert consensus definition for use in clinical trials. ERJ Open Res 2019; 5: 00147-2018 [https://doi.org/10.1183/23120541.00147-2018].

This article has supplementary material available from openres.ersjournals.com.

Received: Sept 042018 | Accepted after revision: Dec 052018

Copyright $\odot E R S$ 2019. This article is open access and distributed under the terms of the Creative Commons Attribution Non-Commercial Licence 4.0. 


\section{Introduction}

Primary ciliary dyskinesia (PCD) is a genetically and clinically heterogeneous disorder, usually inherited as an autosomal recessive condition [1]. It is estimated to affect 1 per 10000-20000 Europeans and is considerably more common in some populations [2-4]. However, many patients remain undiagnosed because physicians do not recognise the pattern of symptoms, because symptoms can be atypical, access to diagnostic reference centres is geographically limited, and diagnostic testing is complex and may miss some subtle cases $[2,5-8]$. Impaired mucociliary clearance typically causes neonatal otherwise unexplained respiratory distress within several hours of birth, persistent wet cough throughout life and progressive bronchiectasis [9]. Patients often have symptoms of chronic rhinosinusitis, fertility issues and conductive hearing impairment. Approximately $50 \%$ of patients have situs inversus [9].

Patients with PCD are susceptible to lower airway infections [10-12]; pulmonary exacerbations are a cause of significant morbidity in patients with this condition $[13,14]$. Epidemiological, clinical and laboratory evidence from other chronic lung diseases suggests that bacterial and viral infections are major causes of exacerbations; environmental pollution might also contribute. Some patients do not recover the accompanying reduction in lung function despite aggressive treatment of the episode with antibiotics and physiotherapy [15]. Pulmonary exacerbations are key outcome measures in clinical trials and epidemiological research into chronic lung diseases. Despite the importance of pulmonary exacerbations in PCD, there has been no consensus definition and individual researchers have used different versions of definitions [15-17]. Although PCD shares some features with cystic fibrosis (CF) and non-CF bronchiectasis, it is important that a separate definition is available for PCD clinical trials because the pathophysiology, symptoms and prognosis differ between the different diseases $[11,18]$.

A multidisciplinary, international panel with an interest in PCD aimed to develop a consensus statement for the definition of pulmonary exacerbations in children and adults with PCD for use in clinical trials and other research. The process included face-to-face meetings at two BEAT-PCD meetings (www.beatpcd. org; April 2017 and February 2018 [19, 20]), e-surveys and reviews of the literature.

\section{Methods}

\section{Participants}

22 clinicians from 17 countries met during a BEAT-PCD conference in Valencia, Spain in April 2017. The panel reflected the disciplines and countries of delegates attending the conference, and included 19 paediatric chest physicians, one adult chest physician and one nurse specialist; clinicians were from Europe (Northern, Southern, Western and Eastern areas represented), Western Asia, the Middle East and Australia.

Affiliations: ${ }^{1}$ Primary Ciliary Dyskinesia Centre, NIHR Southampton Biomedical Research Centre, University of Southampton and University Hospital Southampton NHS Foundation Trust, Southampton, UK. ${ }^{2}$ Pulmonology Dept, Centro Hospitalar S. João, Porto, Portugal. ${ }^{3}$ Faculty of Medicine, Porto University, Porto, Portugal. ${ }^{4}$ Dept of Paediatrics, University Hospital Gasthuisberg, Leuven, Belgium. ${ }^{5}$ PCD Family Support Group, UK. ${ }^{6}$ Paediatric Pulmonology Unit, Paediatrics Dept, Centro Hospitalar Lisboa Norte, Lisbon Academic Medical Centre, Lisbon, Portugal. ${ }^{7}$ Paediatric Dept of Allergy and Lung Diseases, Oslo University Hospital, Oslo, Norway. ${ }^{8}$ Association des Patients Ayant une Dyskinésie Ciliaire Primitive, France. ${ }^{9}$ Division of Paediatric Pulmonology and Allergology, Dept of Paediatrics and Adolescent Medicine, Medical University of Graz, Graz, Austria. ${ }^{10}$ Schneider Children's Medical Center of Israel, Petach-Tikva and Sackler School of Medicine, Tel Aviv University, Tel Aviv, Israel. ${ }^{11}$ Dept of Pediatric Pulmonology, VU University Medical Center, Amsterdam, The Netherlands. ${ }^{12}$ Dept of Paediatric Pneumology, University Children's Hospital of Ruhr University, Bochum, Germany. ${ }^{13}$ Institute of Social and Preventive Medicine, University of Bern, Bern, Switzerland. ${ }^{14}$ Paediatric Respiratory Medicine, University Children's Hospital of Bern, University of Bern, Bern, Switzerland. ${ }^{15}$ Host Defence Unit, Royal Brompton and Harefield NHS Foundation Trust, London, UK ${ }^{16}$ Imperial College London, London, UK. ${ }^{17}$ Dept of Respiratory Medicine, University Hospitals Leuven, Leuven, Belgium. ${ }^{18}$ Service de Pneumologie, Hôpital Intercommunal de Créteil, DHU A-TVB, Inserm U955, Université Paris Est-Créteil, Créteil, France. ${ }^{19}$ Section of Pediatric Allergy, Pulmonology and Cystic Fibrosis, Hospital Vall d'Hebron, Universitat Autónoma de Barcelona, CIBERER, ISCIII, Barcelona, Spain. ${ }^{20}$ Danish PCD \& chILD Centre, CF Centre Copenhagen Paediatric Pulmonary Service, ERN Accredited for PCD and CF Health Care, Dept of Paediatrics and Adolescent Medicine, Copenhagen University Hospital, Rigshospitalet, Copenhagen, Denmark. ${ }^{21}$ Dept of Pediatric Pulmonology, University Medical Faculty, Ankara, Turkey. ${ }^{22}$ Paediatric Dept, Second Faculty of Medicine, Charles University and Motol University Hospital, Prague, Czech Republic. ${ }^{23}$ Vall d'Hebron Research Institute, Respiratory Disease Dept, Hospital Vall d'Hebron, CIBER, Barcelona, Spain. ${ }^{24}$ Dept of Respiratory Medicine, Hannover Medical School, Hanover, Germany. ${ }^{25}$ PCD Service, Dept of Respiratory and Sleep Medicine, Royal Children's Hospital, Melbourne, Australia. ${ }^{26}$ Primary Ciliary Dyskinesia Centre, Dept of Woman and Child Health (SDB), University of Padova, Padua, Italy. ${ }^{27}$ Medical School, University of Cyprus, Nicosia, Cyprus. ${ }^{28}$ Primary Ciliary Dyskinesia Centre, Dept of Paediatric Respiratory Medicine, Imperial College and Royal Brompton Hospital, London, UK.

Correspondence: Jane S. Lucas, Primary Ciliary Dyskinesia Centre, Southampton University Hospital, Mailpoint 803 F Level, Tremona Road, Southampton, S016 6YD, UK. E-mail: jlucas1Asoton.ac.uk 
Following the conference and before starting the modified Delphi surveys we purposely recruited an additional five adult physicians, three patient representatives and a physiotherapist. The additional members received minutes of the meeting in Valencia. The activities of the panel were coordinated by two facilitators (J.S.L. and S.C.) who also contributed to the consensus and a PCD Research Fellow (F.G.) who did not participate in the e-survey voting. Since the consensus concentrates on lower respiratory tract exacerbations, the panel did not include any otorhinolaryngologists. The composition of the panel is outlined in supplementary table S1.

\section{Literature search}

We conducted a systematic literature search to find clinical research studies which had used pulmonary exacerbations in PCD patients as a variable. We searched PubMed from January 1, 2000 to April 1, 2017 using the search terms (ciliary dyskinesia, primary/OR ciliary motility disorders/OR Kartagener's syndrome/) AND exacerbation. We excluded reviews, editorials and case reports. We additionally reviewed literature for definitions of pulmonary exacerbations in patients with $\mathrm{CF}$ and non-CF bronchiectasis. The definitions used in the PCD, CF and bronchiectasis literature were discussed at the first face-to-face meeting and sent out to the group afterwards, providing a framework for the e-Delphi surveys.

\section{Reaching a consensus}

During the first meeting, it was unanimously agreed that the panel's aim was to provide a consensus for the definition of pulmonary exacerbations in PCD for children and adults participating in clinical research. As a starting point the panel decided that we should concentrate on lower respiratory tract exacerbations; although upper respiratory tract exacerbations cause significant morbidity in PCD, we considered that exacerbations of the upper and lower respiratory tract often occur separately, and have different prognostic implications. We decided to use an e-Delphi approach with $80 \%$ agreement signifying consensus. In brief, there were four rounds of e-surveys (www.isurvey.soton.ac.uk). For each survey, participants were sent instructions and a link via e-mail, then a second reminder to respond within 2 weeks. Each survey was comprised of questions in a variety of appropriate formats, including single and multiple responses, rankings of importance, and open text boxes (surveys 1-4: supplementary material). Participants had opportunities to provide free-text comments or explanations. Following each round, the quantitative and qualitative data were analysed using appropriate descriptive statistics or content analyses; results were presented to the panel in an anonymised format before completing the next round, with qualitative data presented in thematic areas. Where we failed to reach consensus, questions were modified in subsequent rounds, informed by the free-text comments. For ranked scores, a weighting was given equating to the number of items ranked. If, for example, there were three options for the format of the definition (simple list with equal weighting, list with weighted scoring, and major and minor criteria) and a respondent ranked these first, second and third, then the first format received 3 points, the second format received 2 points and the third format received 1 point. The total score for each format from all respondents provided a combined ranking score.

The primary focus of the first survey was to decide the relative importance to the definition of 1) changes in symptoms, 2) changes in clinical investigations and 3) a physician's decision to treat. We additionally enquired about the impact of exacerbations on patients, their families and society. In the second survey, we further examined which criteria should be used to define an exacerbation and whether any criteria should be an absolute requirement for the definition. Participants were able to modify decisions from previous rounds having seen the voting and comments from other panel members. In the third survey, we considered the number of criteria that should be listed, how many should be present to define an exacerbation and which of the following formats the definition should take: 1) a list of criteria with equal weighting, 2) a list of criteria with varied weighting or 3) major and minor criteria. Participants were asked to rank a list of nine criteria (symptoms, investigations and physician's decision to treat) to provide a weighting for each criterion (on a scale of 1-3) and to indicate for each criterion whether it could be considered as a major or minor criterion for defining pulmonary exacerbations.

16 members of the panel met during a BEAT-PCD conference in Lisbon, Portugal in February 2018 to discuss the final wording of each element of the survey. Finally, the definition was circulated to the whole panel via the fourth e-survey to seek agreement for the definition.

\section{Results}

The systematic literature search identified eight articles of which five were excluded (two reviews, one case report and two did not include PCD patients). The panel reviewed the included articles [15-17] and proposed one additional PCD clinical trial, but eventually this study was not included because it had not used exacerbations as an outcome variable [21]. Details of the studies are summarised in table 1. In addition, we reviewed 14 articles to understand how exacerbations have been defined in clinical trials 


\begin{tabular}{|c|c|c|c|c|}
\hline $\begin{array}{l}\text { First author } \\
\text { [ref.] }\end{array}$ & Study aims & $\begin{array}{c}\text { Study } \\
\text { population }\end{array}$ & $\begin{array}{l}\text { Method used to } \\
\text { develop the } \\
\text { definition }\end{array}$ & $\begin{array}{l}\text { Definition of } \\
\text { exacerbation }\end{array}$ \\
\hline Kobbernagel [16] & $\begin{array}{l}\text { Protocol for randomised } \\
\text { controlled trial to } \\
\text { determine the efficacy } \\
\text { and safety of } \\
\text { azithromycin } \\
\text { maintenance therapy }\end{array}$ & $\begin{array}{l}\text { PCD children } \\
\text { aged }>7 \text { years } \\
\text { and adults }\end{array}$ & $\begin{array}{c}\text { Face-to-face } \\
\text { discussion at } \\
\text { BESTCILIA study } \\
\text { meeting }\end{array}$ & $\begin{array}{c}\text { Either } \\
\text { Respiratory symptoms } \\
\text { (not listed) leading to } \\
\text { start of systemic } \\
\text { antibiotic treatment, } \\
\text { irrespective of results } \\
\text { of bacterial culture } \\
\text { or } \\
\text { Decline in FEV } \% \text { pred } \\
\geqslant 10 \% \text { relative to the } \\
\text { FEV } 1 \% \text { pred at } \\
\text { randomisation, } \\
\text { irrespective of whether } \\
\text { antibiotics are } \\
\text { prescribed }\end{array}$ \\
\hline RatJen [17] & $\begin{array}{c}\text { Changes in airway } \\
\text { inflammation during } \\
\text { pulmonary } \\
\text { exacerbations }\end{array}$ & $\begin{array}{l}\text { Cystic fibrosis } \\
\text { and PCD } \\
\text { children aged } \\
>6 \text { years }\end{array}$ & $\begin{array}{l}\text { Researcher } \\
\text { defined }\end{array}$ & $\begin{array}{l}\text { Increase in respiratory } \\
\text { symptoms (not listed) } \\
\text { treated with oral } \\
\text { antibiotics }\end{array}$ \\
\hline SUNTHER [15] & $\begin{array}{l}\text { Recovery of baseline } \\
\text { lung function after } \\
\text { pulmonary exacerbation }\end{array}$ & PCD children & $\begin{array}{l}\text { Researcher } \\
\text { defined }\end{array}$ & $\begin{array}{l}\text { A change in respiratory } \\
\text { status for which } \\
\text { intravenous antibiotics } \\
\text { were prescribed }\end{array}$ \\
\hline
\end{tabular}

involving CF and bronchiectasis patients in general (supplementary table S2) [22-35]. All criteria identified in the literature reviews were considered in our Delphi surveys.

The response rates for the four e-surveys were 97\%, 93\%, 84\% and $84 \%$ (supplementary table S1). In the first survey there was agreement that pulmonary exacerbations are a key outcome measure for use in clinical trials in PCD (97\%), and that exacerbations have a significant effect on quality of life (97\%), on missed days from work/school (93\%) and on long-term health outcomes (86\%). There was poor consensus on whether patients make a full recovery after exacerbations.

Through the iterative process of surveys and face-to-face meetings (table 2 and supplementary table S3) the panel decided that no single item was an absolute requirement. Changes in clinical symptoms were rated most highly to contribute to the definition, without a requirement for defining the duration of symptoms (table 2). In terms of investigations, only a change in pulmonary function (forced expiratory volume in $1 \mathrm{~s}$ ) and new radiographic changes received initial 75\% agreement for being included in a list of criteria that might contribute to the definition, and the panel discounted the role of raised C-reactive protein, erythrocyte sedimentation rate, and white cell and neutrophil counts. Some respondents commented that including any investigations in the definition might complicate research protocols and it was finally agreed that the definition should not require access to spirometry or radiography.

The need for a simple approach was expressed throughout all stages. Using experience from CF and non-CF bronchiectasis, we asked participants to rank three formats which could be used for the definition: a list of criteria with equal weighting, a scoring system with differential weighting of items or a definition using minor and major criteria. Participants without experience of using definitions did not participate in this part of the voting. A simple list of criteria with equal weighting was considered the best approach (supplementary table S4). Several respondents commented on their reason for this approach, explaining that a simple approach is easiest for use in clinical trials and that the statistical rationale does not yet exist for a weighted approach.

A consensus ( $>80 \%$ participant approval) definition of a pulmonary exacerbation in children and adults with PCD for use in clinical research was agreed as the presence of three or more of the following seven items: 1) increased cough, 2) change in sputum volume and/or colour, 3) increased shortness of breath 


\begin{tabular}{|c|c|c|c|c|}
\hline \multirow[t]{2}{*}{ Potential criteria for inclusion } & \multicolumn{2}{|c|}{ Survey $2^{\#}$} & \multirow{2}{*}{$\begin{array}{l}\text { Survey } 3^{\Uparrow} \\
\text { calculated } \\
\text { ranking } \\
\text { (1=most } \\
\text { important) }\end{array}$} & \multirow{2}{*}{$\begin{array}{l}\text { Survey } 4^{+} \\
\quad \% \\
\text { agreement }\end{array}$} \\
\hline & $\begin{array}{l}\text { Mean } \\
\text { score }\end{array}$ & $\begin{array}{c}\% \\
\text { agree }\end{array}$ & & \\
\hline Change in sputum volume and/or colour & 1.54 & 93 & 2 & 96 \\
\hline Increased cough & 1.64 & 89 & 1 & 100 \\
\hline New/increased haemoptysis & 1.86 & 79 & 8 & 92 \\
\hline $\begin{array}{l}\text { Increased shortness of breath (parent/patient } \\
\text { perceived) }\end{array}$ & 1.54 & 100 & 3 & 92 \\
\hline Increased respiratory rate & 2.14 & 64 & & \\
\hline Increased chest discomfort/chest pain & 2.07 & 75 & & \\
\hline Malaise, tiredness, fatigue or lethargy & 2.14 & 68 & 7 & 92 \\
\hline Decreased activity & 2.54 & NA & & \\
\hline Decreased exercise tolerance & 2.14 & 71 & & \\
\hline Temperature $>38^{\circ} \mathrm{C}$ & 1.96 & 82 & 9 & 84 \\
\hline Anorexia or weight loss & 2.50 & NA & & \\
\hline Change in physical examination of the chest & 2.29 & NA & & \\
\hline Increased crepitations/crackles & 2.21 & 68 & & \\
\hline Increased wheeze & 2.43 & NA & & \\
\hline $\begin{array}{l}\text { New radiographic changes indicative of a } \\
\text { pulmonary infection }\end{array}$ & 2.18 & 75 & 5 & \\
\hline $\begin{array}{l}\text { Decrease in pulmonary function of } \geqslant 10 \% \text { from } \\
\text { a previously recorded value (FEV } 1 \% \text { pred or } \\
\text { FVC } \% \text { pred) }\end{array}$ & 2.11 & 75 & 4 & \\
\hline Raised C-reactive protein & 2.79 & NA & & \\
\hline Prolonged erythrocyte sedimentation rate & 3.39 & NA & & \\
\hline Raised white cell count & 3.00 & NA & & \\
\hline Raised neutrophil count & 2.96 & NA & & \\
\hline $\begin{array}{l}\text { Physician decision to change treatment because } \\
\text { of perceived change in condition }\end{array}$ & & & 6 & 92 \\
\hline \multicolumn{5}{|c|}{ 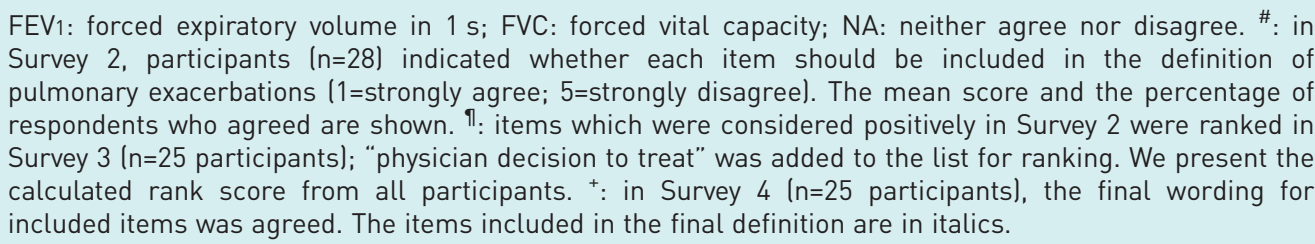 } \\
\hline
\end{tabular}

perceived by the patient or parent, 4) decision to start or change antibiotic treatment because of perceived pulmonary symptoms, 5) malaise, tiredness, fatigue or lethargy, 6) new or increased haemoptysis, and 7) temperature $>38^{\circ} \mathrm{C}$ (table 3 ).

\section{Discussion}

A multidisciplinary panel agreed on a consensus definition of pulmonary exacerbations in children and adults with PCD that we anticipate will be used as an outcome in clinical trials. Timing is right for this definition, with the rapidly evolving research into PCD, and the emergence of clinical trials $[16,21]$ and clinical studies [36-39] involving children and adults with PCD. We expect that physicians will continue making informed decisions concerning pulmonary exacerbations in clinical practice. Much discussion occurred in face-to-face meetings to define the scope and methodology. Although upper respiratory tract infections are problematic in PCD, and often coexist with pulmonary infections, we decided that our definition should concentrate on exacerbations of the lower airway. Recognising that PCD is a multiorgan disease including the entire respiratory system, it is noteworthy that upper respiratory tract symptoms are not captured by this definition. The consensus panel deliberately chose not to include specific ear, nose and throat symptoms because exacerbations of the upper and lower respiratory tract often occur separately, and have different prognostic implications. Upper respiratory tract symptoms impact on quality of life of patients with PCD [40-42] and a separate consensus statement will be needed prior to clinical trials that have upper airway exacerbations as a clinical outcome measure. However, we appreciate that an increase in 
TABLE 3 Definition of a pulmonary exacerbation for children and adults with primary ciliary dyskinesia (PCD) participating in clinical research

The following definition can be used in clinical research to define a pulmonary exacerbation in children and adults with PCD:

Three or more of the following must be present:

- Increased cough

- Change in sputum volume and/or colour

- Increased shortness of breath perceived by the patient or parent

- Decision to start or change antibiotic treatment because of perceived pulmonary symptoms

- Malaise, tiredness, fatigue or lethargy

- New or increased haemoptysis

- Temperature $>38^{\circ} \mathrm{C}$

upper and lower airway symptoms may occur together and that in some, especially the young, it may be difficult to differentiate.

While definitions for pulmonary exacerbations in $\mathrm{CF}$ and non-CF bronchiectasis informed the initial framework of our discussions, we rapidly focused on our experiences of managing children and adults with PCD. Although PCD shares many features with CF and non-CF bronchiectasis, the panel strongly believed that this distinct syndrome required a bespoke definition since pathophysiology, symptoms and prognosis differ. Unlike a recent symptom-based definition for non-CF bronchiectasis [35], we decided that proposing a timeframe (e.g. increased cough for $48 \mathrm{~h}$ ) was not possible because of lack of evidence; we propose that information concerning duration of symptoms which might indicate a significant exacerbation should be captured during future validation studies. These would also be able to test the robustness of using nonspecific symptoms such as temperature $>38^{\circ} \mathrm{C}$ and malaise. We decided that it was feasible to develop a definition applicable to both children and adults, and we therefore recruited additional adult physicians to the panel. There was little discernible difference between opinions of paediatric and adult physicians during voting. The panel benefited from three patient representatives.

The systematic review of PCD literature and the general review of CF and bronchiectasis definitions for exacerbations were conducted prior to the meetings, providing an evidence base to inform potential formats of the definition and the items that might be included. We agreed to an e-Delphi method, accepting agreement by $\geqslant 80 \%$ to signify consensus. Having started with a potential list of 21 criteria, only seven were included in the final definition.

While investigations such as spirometry and chest radiography are undoubtedly useful in clinical practice, participants highlighted the need for a research definition not dependent on access to tests. Minimising research study visits was considered a priority, particularly as PCD is a rare disease and many patients are located geographically distant from the study sites. Moreover, the panel felt that a pulmonary exacerbation could be adequately defined for research purposes without the need for investigations. The definition is therefore based on symptom changes and the decision to change antibiotic medication because of perceived symptoms. The panel acknowledged that many patients are empowered to start antibiotic treatment when they have signs of an exacerbation and therefore it is not a prerequisite for the therapy to be initiated by a physician. These features will enable the definition to be utilised as a patient-reported outcome (PRO) measure.

The definition will need validation and this might lead to newer updated versions. The BEAT-PCD network plans to perform a validation study of the PRO measure in a longitudinal observational study. However, we recognise that pulmonary exacerbations in PCD are difficult to diagnose even in a clinical setting, and that the physician with access to sputum culture remains at risk of false-positive and false-negative cases. In the experience of the expert panel, diagnosing exacerbations in PCD is confounded by various peculiarities of the condition; in particular, patients have a wet cough even when well, and the cough continues after antibiotic treatment, "technically acceptable" lung function parameters can vary $>10 \%$ within the same clinic session and reversible atelectasis occurs on chest radiography even "when well". Similar to definitions in other lung diseases (e.g. non-CF bronchiectasis [35]), the BEAT-PCD panel decided to use a combination of symptoms in our definition of an exacerbation, particularly as we wanted this to be a PRO without need to access clinical tests. We acknowledge that the definition will not be able to distinguish bacterial from viral or fungal exacerbations, but that was not the prime purpose of the definition, particularly as viral and fungal exacerbations might be equally important determinants of prognosis and quality of life. There simply is not a perfect standard. More detailed definitions might be considered in the future in clinical settings, where the patient has investigations, such as chest radiography 
or spirometry, providing additional supporting evidence of an exacerbation. A separate definition is now needed for exacerbation of upper airway disease.

In summary, our international, multidisciplinary panel proposes a definition of pulmonary exacerbations for children and adults with PCD for use in clinical trials and other research settings. The definition will be validated in a project led by the BEAT-PCD network [20,43]. Importantly, the definition was equally acceptable to health professionals working with children and adults and to patient representatives. We have aimed to deliver a definition that will be internationally applicable and can be applied in different research settings.

Conflict of interest: J.S. Lucas reports grants, personal fees and nonfinancial support from Aerocrine/Circassia, grants and personal fees from Vertex, and grants from Parion, outside the submitted work. F. Gahleitner has nothing to disclose. A. Amorim reports personal fees from Zambon and personal fees from Vertex, outside the submitted work. M. Boon reports a postdoctoral research grant from KOOR, University Hospital Leuven, outside the submitted work. P. Brown has nothing to disclose. C. Constant has nothing to disclose. S. Cook has nothing to disclose. S. Crowley has nothing to disclose. D.M.S. Destouches has nothing to disclose. E. Eber has nothing to disclose. H. Mussaffi has nothing to disclose. E. Haarman has nothing to disclose. A. Harris has nothing to disclose. C. Koerner-Rettberg has nothing to disclose. C.E. Kuehni has nothing to disclose. P. Latzin reports personal fees from Vertex, Novartis, Roche, Polyphor, Vifor, Gilead, Schwabe, Zambon, Santhera and Vertex, outside the submitted work. M.R. Loebinger reports personal fees from Bayer, Griffols, Polyphor and Raptor, and other support from Parion, outside the submitted work. N. Lorent reports personal fees from Chiesi, and nonfinancial support from Insmed and Mylan, outside the submitted work. B. Maitre has nothing to disclose. A. Moreno-Galdó reports personal fees from AbbVie, and other support from AbbVie, Actelion and Novartis, outside the submitted work. K.G. Nielsen has nothing to disclose. U. Özçelik has nothing to disclosure L.K.D. Philipsen has nothing to disclose. P. Pohunek reports personal fees from Novartis, Sandoz and Teva, grants from Teva, and personal fees from Stallergenes, S\&D Pharma, ALK and Boehringer Ingelheim, outside the submitted work. E. Polverino reports personal fees from Bayer, Insmed and Grifols, Zambon, grants and personal fees from Chiesi, and personal fees from Polyphor, during the conduct of the study; none of these fees and grants were strictly related with the topic of this manuscript. J. Rademacher has nothing to disclose. P. Robinson has nothing to disclose. D. Snijders has nothing to disclose. P. Yiallouros has nothing to disclose. S.B. Carr reports personal fees and other support from Vertex Pharmaceuticals, other support from Chiesi Ltd, personal fees from Teva Pharmaceutical Industries and other support from Pharmaxis Pharmaceuticals Ltd, outside the submitted work.

Support statement: This study was supported European Union COST Action BM 1407. Funding information for this article has been deposited with the Crossref Funder Registry.

\section{References}

1 Lucas JS, Walker WT, Kuehni CE, et al. Primary ciliary dyskinesia. In: Cordier J-F, ed. Orphan Lung Diseases (ERS Monograph). Sheffield, European Respiratory Society, 2011; pp. 1-19.

2 Kuehni CE, Frischer T, Strippoli MP, et al. Factors influencing age at diagnosis of primary ciliary dyskinesia in European children. Eur Respir J 2010; 36: 1248-1258.

3 O'Callaghan C, Chetcuti P, Moya E. High prevalence of primary ciliary dyskinesia in a British Asian population. Arch Dis Child 2010; 95: 51-52.

4 Onoufriadis A, Paff T, Antony D, et al. Splice-site mutations in the axonemal outer dynein arm docking complex gene CCDC114 cause primary ciliary dyskinesia. Am J Hum Genet 2013; 92: 88-98.

5 Lucas JS, Barbato A, Collins SA, et al. European Respiratory Society guidelines for the diagnosis of primary ciliary dyskinesia. Eur Respir J 2017; 49: 1601090.

6 Behan L, Dimitrov BD, Kuehni CE, et al. PICADAR: a diagnostic predictive tool for primary ciliary dyskinesia Eur Respir J 2016; 47: 1103-1112.

7 Behan L, Dunn Galvin A, Rubbo B, et al. Diagnosing primary ciliary dyskinesia: an international patient perspective. Eur Respir J 2016; 48: 1096-1107.

8 Lucas JS, Leigh MW. Diagnosis of primary ciliary dyskinesia: searching for a gold standard. Eur Respir J 2014; 44 $1418-1422$.

9 Goutaki M, Meier AB, Halbeisen FS, et al. Clinical manifestations in primary ciliary dyskinesia: systematic review and meta-analysis. Eur Respir J 2016; 48: 1081-1095.

10 Alanin MC, Nielsen KG, von Buchwald C, et al. A longitudinal study of lung bacterial pathogens in patients with primary ciliary dyskinesia. Clin Microbiol Infect 2015; 21: 1093.

11 Lucas JS, Alanin MC, Collins S, et al. Clinical care of children with primary ciliary dyskinesia. Expert Rev Respir Med 2017; 11: 779-790.

12 Walker WT, Jackson CL, Allan RN, et al. Primary ciliary dyskinesia ciliated airway cells show increased susceptibility to Haemophilus influenzae biofilm formation. Eur Respir J 2017; 50: 1700612.

13 Behan L, Rubbo B, Lucas JS, et al. The patient's experience of primary ciliary dyskinesia: a systematic review. Qual Life Res 2017; 26: 2265-2285.

14 Schofield LM, Horobin HE. Growing up with Primary Ciliary Dyskinesia in Bradford, UK: exploring patients experiences as a physiotherapist. Physiother Theory Pract 2014; 30: 157-164.

15 Sunther M, Bush A, Hogg C, et al. Recovery of baseline lung function after pulmonary exacerbation in children with primary ciliary dyskinesia. Ped Pulm 2016; 51: 1362-1366.

16 Kobbernagel HE, Buchvald FF, Haarman EG, et al. Study protocol, rationale and recruitment in a European multi-centre randomized controlled trial to determine the efficacy and safety of azithromycin maintenance therapy for 6 months in primary ciliary dyskinesia. BMC Pulm Med 2016; 16: 104.

17 Ratjen F, Waters V, Klingel M, et al. Changes in airway inflammation during pulmonary exacerbations in patients with cystic fibrosis and primary ciliary dyskinesia. Eur Respir J 2016; 47: 829-836. 
18 Lucas JS, Carroll M. Primary ciliary dyskinesia and cystic fibrosis: different diseases require different treatment. Chest 2014; 145: 674-676.

19 Rubbo B, Lucas JS. Clinical care for primary ciliary dyskinesia: current challenges and future directions. Eur Respir Rev 2017; 26: 170023.

20 Halbeisen F, Hogg C, Alanin MC, et al. Proceedings of the 2nd BEAT-PCD conference and 3rd PCD training school: part 1. BMC Proc 2018; 12: Suppl. 2, 1.

21 Paff T, Daniels JM, Weersink EJ, et al. A randomised controlled trial on the effect of inhaled hypertonic saline on quality of life in primary ciliary dyskinesia. Eur Respir J 2017; 49: 1601770.

22 Fuchs HJ, Borowitz DS, Christiansen DH, et al. Effect of aerosolized recombinant human DNase on exacerbations of respiratory symptoms and on pulmonary function in patients with cystic fibrosis. The Pulmozyme Study Group. N Engl J Med 1994; 331: 637-642.

23 Kanga J, Kuhn R, Craigmyle L, et al. Cystic fibrosis clinical score: a new scoring system to evaluate acute pulmonary exacerbation. Clin Ther 1999; 21: 1343-1356.

24 Rosenfeld M, Emerson J, Williams-Warren J, et al. Defining a pulmonary exacerbation in cystic fibrosis. J Pediatr 2001; 139: 359-365.

25 Rabin HR, Butler SM, Wohl ME, et al. Pulmonary exacerbations in cystic fibrosis. Ped Pulm 2004; 37: 400-406.

26 Treggiari MM, Rosenfeld M, Mayer-Hamblett N, et al. Early anti-pseudomonal acquisition in young patients with cystic fibrosis: rationale and design of the EPIC clinical trial and observational study. Contemp Clin Trials 2009; 30: $256-268$

27 Saiman L, Anstead M, Mayer-Hamblett N, et al. Effect of azithromycin on pulmonary function in patients with cystic fibrosis uninfected with Pseudomonas aeruginosa: a randomized controlled trial. JAMA 2010; 303: $1707-1715$.

28 Bilton D, Canny G, Conway S, et al. Pulmonary exacerbation: towards a definition for use in clinical trials. Report from the EuroCareCF Working Group on outcome parameters in clinical trials. J Cyst Fibros 2011; 10: Suppl. 2 , S79-S81.

29 Rosenfeld M, Ratjen F, Brumback L, et al. Inhaled hypertonic saline in infants and children younger than 6 years with cystic fibrosis: the ISIS randomized controlled trial. JAMA 2012; 307: 2269-2277.

30 Kapur N, Masters IB, Morris PS, et al. Defining pulmonary exacerbation in children with non-cystic fibrosis bronchiectasis. Ped Pulm 2012; 47: 68-75.

31 Lechtzin N, Mayer-Hamblett N, West NE, et al. Home monitoring of patients with cystic fibrosis to identify and treat acute pulmonary exacerbations. eICE study results. Am J Respir Crit Care Med 2017; 196: 1144-1151.

32 Lechtzin N, West N, Allgood S, et al. Rationale and design of a randomized trial of home electronic symptom and lung function monitoring to detect cystic fibrosis pulmonary exacerbations: the early intervention in cystic fibrosis exacerbation (eICE) trial. Contemp Clin Trials 2013; 36: 460-469.

33 Waters V, Ratjen F. Pulmonary exacerbations in children with cystic fibrosis. Ann Am Thorac Soc 2015; 12: Suppl. 2, S200-S206.

34 Brill SE, Patel AR, Singh R, et al. Lung function, symptoms and inflammation during exacerbations of non-cystic fibrosis bronchiectasis: a prospective observational cohort study. Respir Res 2015; 16: 16.

35 Hill AT, Haworth CS, Aliberti S, et al. Pulmonary exacerbation in adults with bronchiectasis: a consensus definition for clinical research. Eur Respir J 2017; 49: 1700051.

36 Werner C, Lablans M, Ataian M, et al. An international registry for primary ciliary dyskinesia. Eur Respir J 2016; 47: 849-859.

37 Goutaki M, Maurer E, Halbeisen FS, et al. The international primary ciliary dyskinesia cohort (iPCD Cohort) methods and first results. Eur Respir J 2017; 49: 1601181.

38 Halbeisen FS, Goutaki M, Spycher BD, et al. Lung function in patients with primary ciliary dyskinesia: an iPCD Cohort study. Eur Respir J 2018; 52: 1801040.

39 Goutaki M, Halbeisen FS, Spycher BD, et al. Growth and nutritional status, and their association with lung function: a study from the international Primary Ciliary Dyskinesia Cohort. Eur Respir J 2017; 50: 1701659.

40 Behan L, Leigh MW, Dell SD, et al. Validation of a health-related quality of life instrument for primary ciliary dyskinesia (QOL-PCD). Thorax 2017; 72: 832-839.

41 Dell SD, Leigh MW, Lucas JS, et al. Primary ciliary dyskinesia: first health-related quality-of-life measures for pediatric patients. Ann Am Thorac Soc 2016; 13: 1726-1735.

42 Lucas JS, Behan L, Dunn Galvin A, et al. A quality-of-life measure for adults with primary ciliary dyskinesia: QOL-PCD. Eur Respir J 2015; 46: 375-383.

43 Rubbo B, Behan L, Dehlink E, et al. Proceedings of the COST action BM1407 inaugural conference BEAT-PCD: translational research in primary ciliary dyskinesia - bench, bedside, and population perspectives. BMC Proc 2016; 10: 66 . 